\title{
Modeling of InGaN/Si tandem cells: comparison between 2-contacts/4-contacts
}

\author{
Walid El-Huni ${ }^{1,2, a}$, Anne Migan ${ }^{1,2}$, David Alamarguy ${ }^{1}$, and Zakaria Djebbour ${ }^{1,3}$ \\ 1 GeePs, UMR 8507, CNRS, Centrale Supélec, UPsud, UPMC, 11 Rue Joliot-Curie, 91192 Gif-sur-Yvette Cedex, France \\ 2 Université Pierre et Marie Curie, UPMC, 4 Place Jussieu, 75005 Paris, France \\ 3 Département des Sciences Physiques, UVSQ, 45 Avenue des États-Unis, 78035 Versailles, France
}

Received: 18 November 2016 / Received in final form: 4 January 2017 / Accepted: 26 January 2017

(c) W. El-Huni et al., published by EDP Sciences, 2017

\begin{abstract}
Due to its electrical and optical interesting properties, InGaN alloy is being intensively studied to be combined with silicon in order to achieve low-cost high-efficiency solar cell. However, a relatively thick monophasic layer of InGaN is difficult to grow due to the relaxation issue in material. This issue can be avoided by semibulk structure. In this work, we present an InGaN/Si double-junction solar cell modeled using Silvaco-ATLAS TCAD software. We have taken into account polarization effect in III-N materials. We have shown that $50 \%$ of indium is needed to ensure the current matching between the top cell and the bottom cell in 2-terminal configuration. Such high indium composition is technologically challenging to grow. Thus, we have modeled a 4-terminals solar cell with relatively low indium composition (In $=25 \%)$ where current matching is not needed. With technologically feasible structural parameters, we have shown that an efficiency near to $30 \%$ can be achieved with InGaN/Si 4-contact tandem cell.
\end{abstract}

\section{Introduction}

Silicon-based tandem solar cell is a promising design for low-cost high-efficiency solar cell. However, it is hard to find a matched-bandgap material with silicon (1.7$1.8 \mathrm{eV})$ [1]. The maximum power conversion efficiency (PCE) for a tandem solar cell is $31.6 \%$ for GaInP/GaAs tandem cell [2]. While GaAs is more expensive compared to silicon $(\mathrm{Si})$. For this reason, many groups have tried to combine III-V material with Si. The record of Si-based tandem solar cell is the one achieved recently with a PCE of $29.8 \%$ [3].

InGaN material has been intensively studied last years to be used for photovoltaic applications. This alloy has a wide-range direct bandgap that varies from $0.7 \mathrm{eV}(\mathrm{InN})$ to $3.4 \mathrm{eV}(\mathrm{GaN})[4,5]$. Its high absorption coefficient [6], allows the use of very thin layer $(<1 \mu \mathrm{m})$ to absorb the majority of incident light. They are more resistant to highenergetic radiations which is beneficial to spacial uses [7].

These advantages make InGaN material interesting for PV applications. However, InGaN-based solar cell has a maximum PCE of $6 \%$ [8]. One of the most important challenges that limits the performance of this material is the growth of high-quality relatively-thick InGaN layer. Due to large lattice mismatch between $\mathrm{InN}$ and $\mathrm{GaN}$, InGaN

\footnotetext{
${ }^{a}$ e-mail: walid.elhuni@geeps. centralesupelec.fr
}

grown layer start to relax through dislocation defects after a certain thickness, called critical thickness $[9,10]$. This critical thickness depends on indium composition to the extend that at $30 \%$ of indium the critical thickness is less than $10 \mathrm{~nm}[11,12]$.

However, a solution that has been initiated by Pantzas et al. [9] in order to avoid the relaxation issue, which is semibulk structure. This structure is obtained by periodically stopping the indium flux, during the growth process, before arriving to the critical thickness. This will lead to the introduction of GaN interlayers. We have previously shown the enhancement of InGaN-based solar cell's performance using semibulk structure [13].

In this work, we aim to study the integration of InGaNbased semibulk-structured solar cell with Si-based solar cell for high-efficiency tandem cell.

\section{Methode}

We have used SILVACO-Atlas for our simulations. SILVACO-Atlas is a finite-element physical-based simulation tool, which solves the three equations: Poisson equation, continuity equations, and transport equations at each node. In this section we explain some of physical models that have been used in our simulations. Parameters' values are listed in Table 1. 
Table 1. Parameters used in simulations.

\begin{tabular}{|c|c|c|c|c|c|}
\hline Parameter & [Unit] & c-Si & $\mathrm{GaN}$ & $\mathrm{InN}$ & $\begin{array}{l}\text { Interpolation } \\
(\mathrm{InGaN})\end{array}$ \\
\hline$a$ & {$[\AA]$} & 5.43 & 3.189 & 3.545 & Linear \\
\hline$E_{g}$ & {$[\mathrm{eV}]$} & 1.08 & 3.42 & 0.76 & Bowing $=1$ \\
\hline \multicolumn{6}{|c|}{ Recombination } \\
\hline$\tau_{n 0}$ & {$[\mathrm{~s}]$} & $1,3 \mathrm{e}-3$ & $5 \mathrm{e}-9$ & $5 \mathrm{e}-9$ & \\
\hline$\tau_{p 0}$ & {$[\mathrm{~s}]$} & $1,3 \mathrm{e}-3$ & $5 e-9$ & $5 e-9$ & \\
\hline$C_{\text {rad }}$ & {$\left[\mathrm{cm}^{3} / \mathrm{s}\right]$} & & $1 \mathrm{e}-8$ & $1 e-8$ & \\
\hline$S_{n}$ & {$[\mathrm{~cm} / \mathrm{s}]$} & 100 & $1 \mathrm{e} 4$ & & \\
\hline$S_{p}$ & {$[\mathrm{~cm} / \mathrm{s}]$} & 100 & $1 \mathrm{e} 4$ & & \\
\hline \multicolumn{6}{|c|}{ Mobility } \\
\hline$\mu_{1 n}$ & {$\left[\mathrm{~cm}^{2} /(\mathrm{V} \mathrm{s})\right]$} & 55.24 & 55 & 30 & Linear \\
\hline$\mu_{2 n}$ & {$\left[\mathrm{~cm}^{2} /(\mathrm{V} \mathrm{s})\right]$} & 1429.23 & 1000 & 1100 & Linear \\
\hline$N_{g n}$ & {$\left[\mathrm{~cm}^{-3}\right]$} & $1.07 \mathrm{e} 17$ & $2 \mathrm{e} 17$ & $8 \mathrm{e} 18$ & Linear \\
\hline$\mu_{1 p}$ & {$\left[\mathrm{~cm}^{2} /(\mathrm{V} \mathrm{s})\right]$} & 49.7 & 3 & 3 & \\
\hline$\mu_{2 p}$ & {$\left[\mathrm{~cm}^{2} /(\mathrm{V} \mathrm{s})\right]$} & 479.37 & 170 & 340 & Linear \\
\hline$N_{g p}$ & {$\left[\mathrm{~cm}^{-3}\right]$} & $1.6 \mathrm{e} 17$ & $3 \mathrm{e} 17$ & $3 \mathrm{e} 17$ & \\
\hline \multicolumn{6}{|c|}{ Polarization } \\
\hline$P_{s p}$ & {$\left[\mathrm{C} / \mathrm{m}^{2}\right]$} & & -0.034 & -0.042 & Bowing $=-0.037$ \\
\hline$e_{33}$ & {$\left[\mathrm{C} / \mathrm{m}^{2}\right]$} & & 0.73 & 0.97 & Linear \\
\hline$e_{31}$ & {$\left[\mathrm{C} / \mathrm{m}^{2}\right]$} & & -0.49 & -0.57 & Linear \\
\hline$C_{33}$ & {$[\mathrm{GPa}]$} & & 398 & 224 & Linear \\
\hline$C_{31}$ & {$[\mathrm{GPa}]$} & & 106 & 92 & Linear \\
\hline
\end{tabular}

\subsection{Electrons and holes mobilities}

For electrons and holes mobilities, we have chosen concentration-dependent mobility:

$$
\begin{aligned}
& \mu_{n 0}\left(\mathrm{~cm}^{2} \mathrm{~V}^{-1} \mathrm{~s}^{-1}\right)=\mu_{1 n}+\frac{\mu_{2 n}-\mu_{1 n}}{1+\left(N / N_{g n}\right)^{\delta_{n}}} \\
& \mu_{p 0}\left(\mathrm{~cm}^{2} \mathrm{~V}^{-1} \mathrm{~s}^{-1}\right)=\mu_{1 p}+\frac{\mu_{2 p}-\mu_{1 p}}{1+\left(N / N_{g p}\right)^{\delta_{p}}}
\end{aligned}
$$

where $\mu_{1}$ and $\mu_{2}$ are the minimum and maximum mobilities, $N$ is the impurity local concentration, $N_{g}$ and $\delta$ are fitting parameters.

\subsection{Recombination processes}

Two recombination processes are considered here: the radiative recombination and the Schokley-Read-Hall recombination (SRH):

Radiative recombination is given by:

$$
R_{n p}^{o p t}\left(\mathrm{~cm}^{-3} \mathrm{~s}^{-1}\right)=C^{o p t}\left(n p-n_{i e}^{2}\right) ;
$$

and Schokley-Read-Hall recombination (SRH), which is a non-radiative recombination, is given by:

$$
R_{s r h}\left(\mathrm{~cm}^{-3} \mathrm{~s}^{-1}\right)=\frac{p n-n_{i e}^{2}}{\tau_{p}\left[n+n_{i e}\right]+\tau_{n}\left[p+n_{i e}\right]}
$$

where $n$ and $p$ are electron and hole concentrations, respectively, $n_{i e}$ is the intrinsic concentration, $\tau_{n}$ and $\tau_{p}$ are electron and hole lifetimes, respectively. For silicon-based solar cell, we have taken into account the dependancy of carriers' lifetime on doping concentration. Surface recombination has been included in our simulations using surface velocity parameters $S_{n}$ and $S_{p}$ for electrons and holes respectively.

\subsection{Bandgap}

The bandgap, $E_{g}$, is calculated using Vegard's law:

$$
E_{g}^{\mathrm{In}_{x} \mathrm{Ga}_{1-x} \mathrm{~N}}(\mathrm{eV})=x E_{g}^{\mathrm{InN}}+(1-x) E_{g}^{\mathrm{GaN}}-b x(1-x)
$$

where $x$ is the indium composition and $b$ is the bowing parameter.

\subsection{Polarization}

III-nitrides are polar materials due to the noncentrosymmetric nature of their crystallographic structure. This causes a spontaneous polarization, $P_{s p}$, that can be calculated for InGaN by:

$$
\begin{aligned}
P_{s p}^{\mathrm{In}_{x} \mathrm{Ga}_{1-x} \mathrm{~N}}\left(\mathrm{C} / \mathrm{m}^{2}\right)= & x P_{s p}^{\mathrm{InN}}+(1-x) P_{s p}^{\mathrm{GaN}} \\
& -b x(1-x) .
\end{aligned}
$$

In addition, due to the lattice difference between the InGaN epilayer and the GaN substrate, the strain causes a piezoelectric-induced polarization, $P_{p z}$, that can be calculated by:

$$
\begin{aligned}
P_{p z}^{\left(\operatorname{In}_{x} \mathrm{Ga}_{1-x} \mathrm{~N}\right)}\left(\mathrm{C} / \mathrm{m}^{2}\right)= & 2 \times R_{s}\left(e_{31}(x)\right. \\
& \left.-\frac{C_{13}(x)}{C_{33}(x)} e_{33}(x)\right) \epsilon(x) \\
\epsilon(x)= & \left(a-a_{0}\right) / a_{0}
\end{aligned}
$$




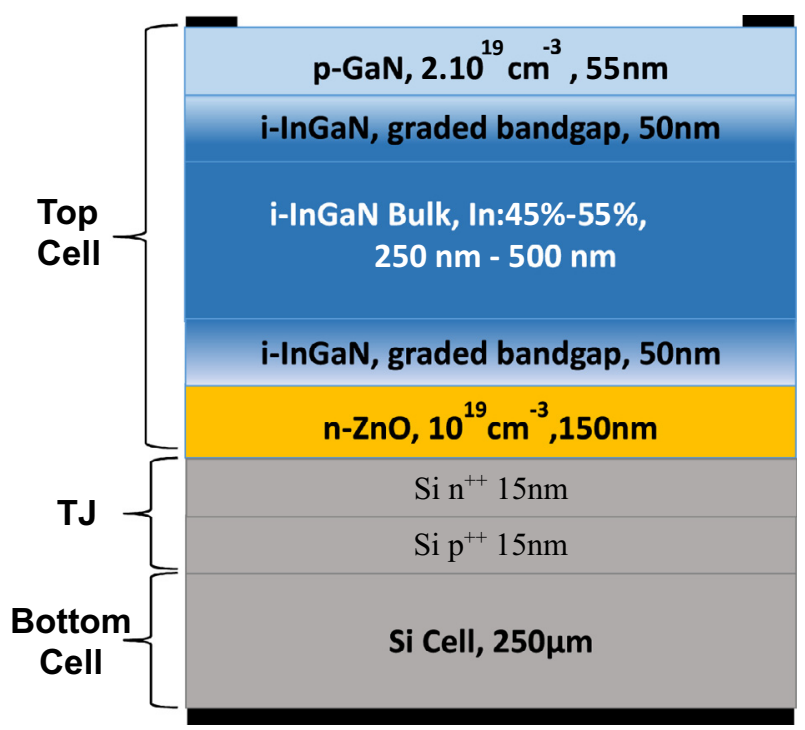

Fig. 1. Modeled structure for InGaN/Si 2-terminal tandem cell. Top cell structure is based on the work of reference [15], and bottom cell structure is based on the work of reference [23].

where $R_{s}$ is the residual strain. $R_{s}=1$ means that the layer is fully strained. $a_{0}$ and $a$ are the initial and stressed lattice constants. The total polarization is the sum of both spontaneous polarization and piezoelectric polarization, taking into account the direction of each.

\section{Results}

In these simulations we have taken into account the attenuation of polarization effect as the number of periods increases as demonstrated experimentally by Bai et al. [14]. We have also lowered the carriers' lifetime in $p$-GaN layer as it shows lower external quantum efficiency (EQE) [15] for lower wavelengths. A bowing parameter of 1 has been used for bandgap calculation. We have used the same value to calculate electron affinity for In$\mathrm{GaN}$, while the maximum valence band varies linearly [16]. More details about the physical and optical models can be found in our previous work [17]. We have also, in the latter work, validated our model by comparing our simulation results to experimental results obtained by other groups $[15,18,19]$, for both InGaN-based top cell and Sibased bottom cell.

First, we show the modeling results for a 2-terminal InGaN/Si tandem cell. The modeled structure is shown in Figure 1. Due to the thermal budget to grow InGaN material, it is not preferable to grow it directly on Sibased junction, because this will deteriorate the tunneling junction which is embedded in Si. For this reason, we have added a $\mathrm{ZnO}$ intermediate layer in the modeled structure.

As we expect that the optimum would be obtained with high indium composition, which is necessary to fulfill the current-matching condition, we have assumed a bulk absorbing layer of InGaN in order to avoid the high barriers that would be caused by semibulk structure. We have also used a graded heterojunctions in both sides of intrinsic layer in order to ensure the band continuity at interfaces. For Si-based bottom cell, the top cell bandgap should be between 1.7 and $1.8 \mathrm{eV}$ in order to achieve the current matching [1]. For this reason, we have varied the indium composition from $45 \%$ to $55 \%$. Using SILAVCOATLAS TCAD software, we have optimized this structure and we show, in Figure 2, that the maximal efficiency of about $28 \%$ is obtained with $50 \%$ of indium and with 400-nm thickness of InGaN absorbing layer. These values, which are needed to fulfill the current-matching condition and to extract the optimal photogenerated current density, are not technologically attainable today.

Using XPS analysis, we have studied the interface between $\mathrm{ZnO}$ and Si. Figure 3 shows the atomic concentration for detected elements in function of sputter time. According to energy positions, we have distinguished between the oxygen $(\mathrm{O})$ that is related to $\mathrm{Zn}$ and the $\mathrm{O}$ that is related to $\mathrm{Si}$. We did the same for Si. The $\mathrm{ZnO}$ was grown using PLD (Pulsed Laser Deposition) with a thickness of $12 \mathrm{~nm}$. Based on a reference sample of $\mathrm{SiO}_{2}$, we have estimated thickness of $\mathrm{SiO}_{x}$ between $\mathrm{ZnO}$ and $\mathrm{Si}$ to be about $3 \mathrm{~nm} \pm 0.5 \mathrm{~nm}$. Introducing this interafacial layer in the modeled structure, we show that beyond $2 \mathrm{~nm}$ of thickness the PCE start to decrease dramatically to extend that at $3 \mathrm{~nm}$ of $\mathrm{SiO}_{x}$ thickness, we do not expect to have a PV response. This is because of the high bandgap of $\mathrm{SiO}_{x}$ that prevents the tunneling process through the tunneling junction. Figure 4 shows the dependence of PCE in function of $\mathrm{SiO}_{x}$ thickness.

Due to the difficulty of achieving a 2-terminal InGaN/Si tandem cell, at least for short-term, we need to study another alternative which is 4-terminal design. The advantage of this design is that it does not require a current matching between top and bottom cell. Consequently, it offers a larger range of bandgaps combination. It has been shown also that 4-terminal design is less sensitive to the variation of solar spectrum during the day [20] and, hence, it has a higher daily-energy yield compared to 2terminal design.

Consequently, we have modeled 4-terminal InGaN/Si tandem cell shown in Figure 5. For bottom cell we have used Si-based PERL-structured solar cell. For top cell we have used InGaN-based semibulk-structured solar cell, with GaN interlayers of $2 \mathrm{~nm}$. We have taken into account the polarization effect of the InGaN. We have varied the indium composition from $20 \%$ to $30 \%$, and the number of periods from 10 to 25 . The InGaN sublayers thickness was varied from $5 \mathrm{~nm}$ to $20 \mathrm{~nm}$. Figure 6 shows the results of total PCE. One can see that the optimum is obtained at $25 \%$ of indium with number of periods between 20 and 25 . The reason of having the optimum at higher number of periods is because that we have taken into account the attenuation of polarization effect with increasing number of periods. However, the InGaN-sublayer thickness should be more than $10 \mathrm{~nm}$ in order to have the maximum efficiency of about $27 \%$. However, the critical thickness of InGaN at $25 \%$ of indium provided by some models is less than $10 \mathrm{~nm}[11,21]$. At $30 \%$ of indium composition, PCE 

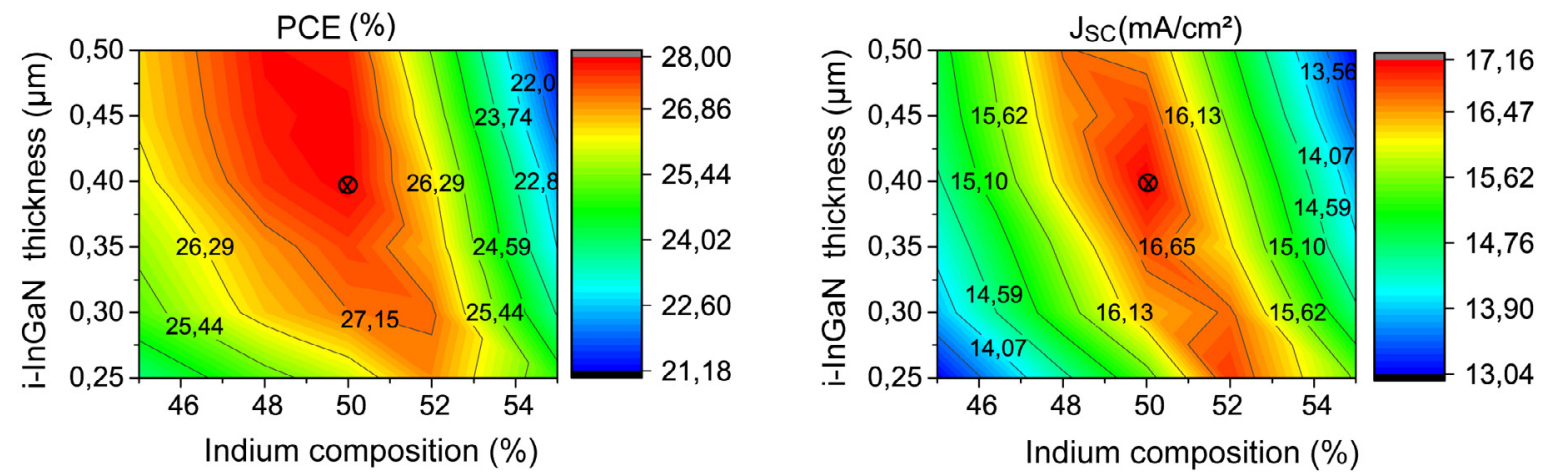

Fig. 2. PCE (left) and $\mathrm{J}_{s c}$ (right) of InGaN/Si 2-terminal tandem cell as a function of indium composition and i-InGaN thickness of InGaN-based top cell.

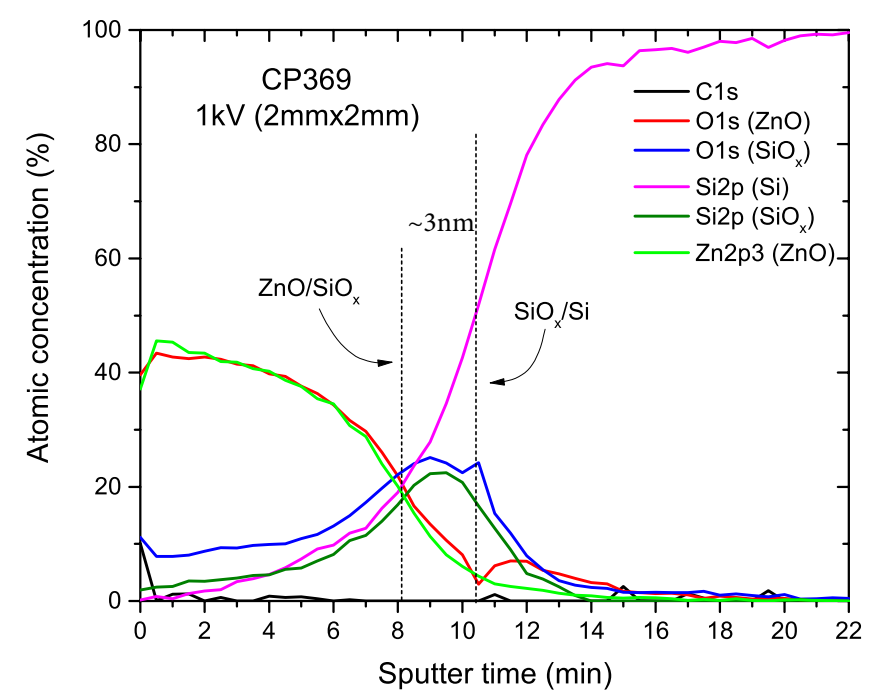

Fig. 3. XPS depth profiles of $\mathrm{Zn}, \mathrm{O}$ and $\mathrm{Si}$, as a function of sputtering time. We have decomposed the $\mathrm{O}$ related to $\mathrm{Si}$ and the $\mathrm{O}$ related to $\mathrm{Zn}$. We have done the same for Si.

decreases. This is because of barriers' height that become more important which decreases the tunneling probability.

We have considered the dichroic mirror (DM) that has been demonstrated experimentally by Young et al. [22], which has a reflectance of $89 \%$ in the region coinciding with the InGaN photoresponse (365-460 nm). At wavelengths beyond $470 \mathrm{~nm}$, the reflectance average is about $4.0 \%$ only. If we take into account the effect of this mirror in our simulations, we show that, in Figure 7, the InGaNsublayer optimal thickness can be reduced to $5 \mathrm{~nm}$, which is less than or in the same order of magnitude of the critical thickness. We show also that efficiencies around $27 \%$ can be obtained with only $20 \%$ of indium.

For both with and without DM, we noticed that the structure with $30 \%$ of indium is more sensitive to the variation of number of periods. This is explained by the fact that at $30 \%$ of indium, the polarization-induced charges at the interfaces increases, which increases the opposite electric field in barriers. As the polarization effect decreases with the increase of number of periods, one can notice the enhancement in PCE for higher number of periods.

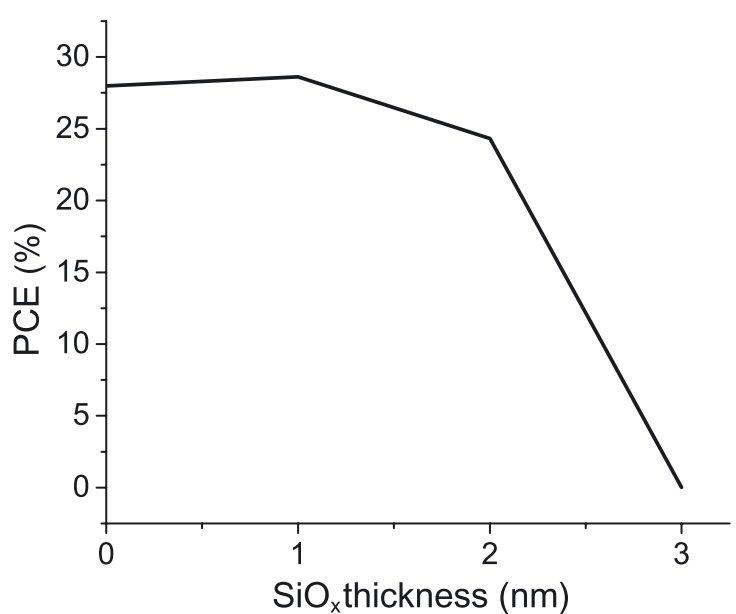

Fig. 4. PCE of InGaN/Si 2-terminal tandem cell as a function of $\mathrm{SiO}_{x}$ interfacial layer thickness.

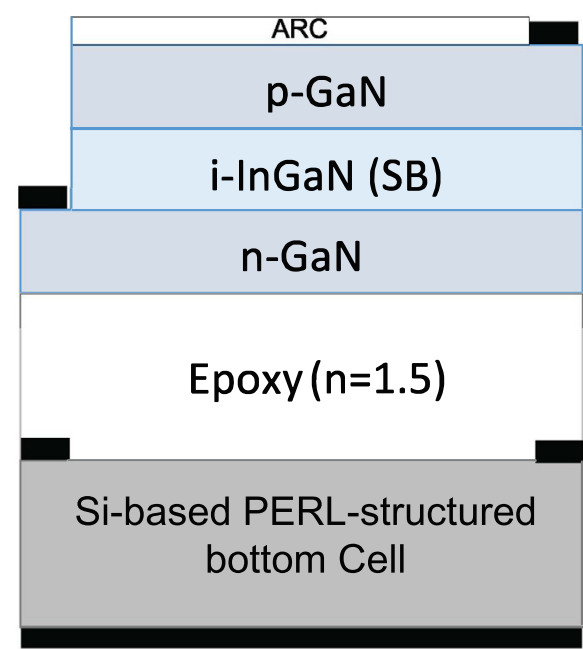

Fig. 5. Modeled structure of InGaN/Si 4-terminal tandem cell.

\section{Conclusion}

Using a realistic modeling, we have shown that InGaN/Si 2-terminal tandem cell is technologically challenging due to the need of high-indium composition 

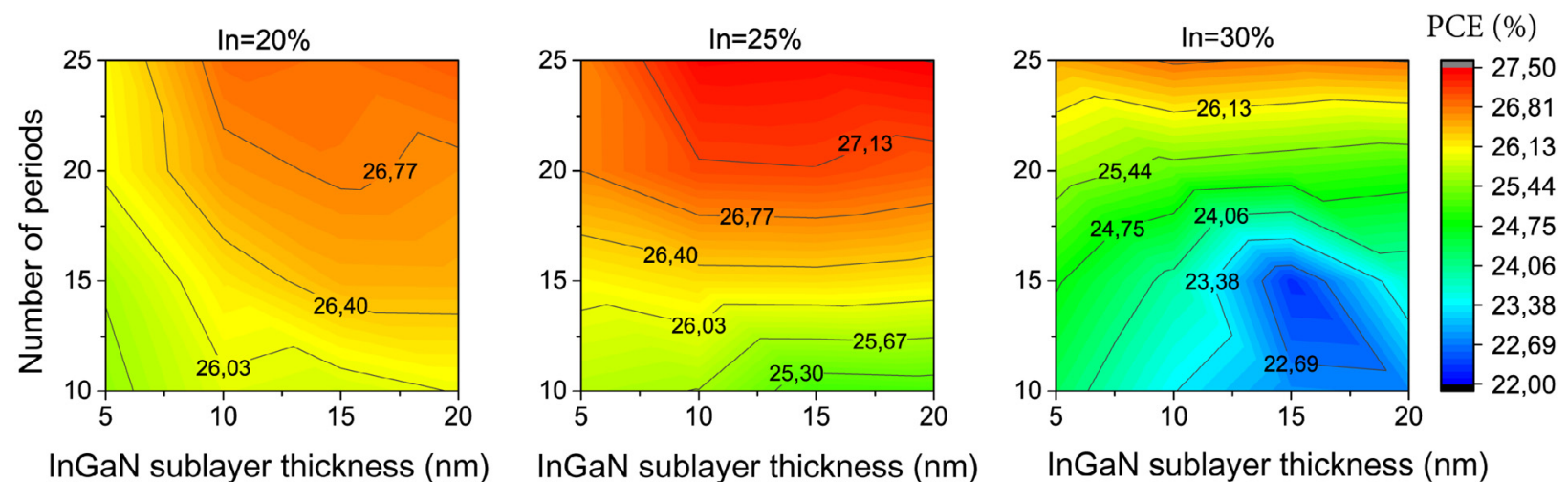

Fig. 6. PCE of InGaN/Si 4-terminal tandem cell as a function of InGaN sublayers' thickness and number of periods. The indium composition has been varied for $20 \%, 25 \%$ and $30 \%$.
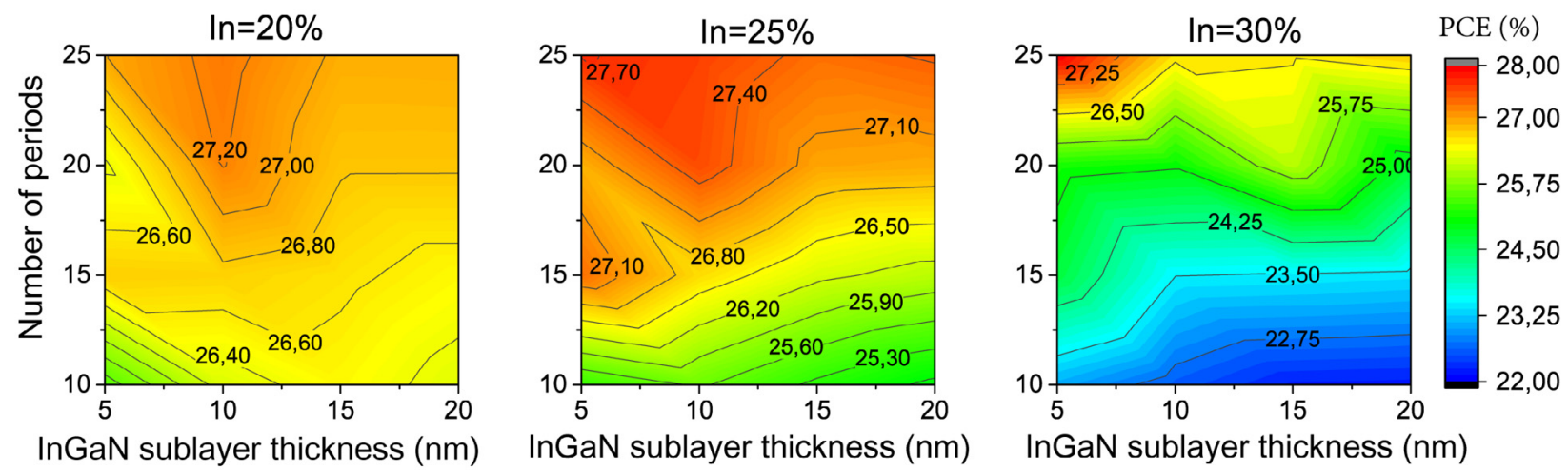

Fig. 7. PCE of InGaN/Si 4-terminal tandem cell as a function of InGaN sublayers' thickness and number of periods. The indium composition has been varied for $20 \%, 25 \%$ and $30 \%$. We have taken into account the DM at the back side of top cell.

(about 50\%) and relatively thick absorbing layer (near $400 \mathrm{~nm}$ ), in order to fulfill the current-matching condition. We have shown also that the $\mathrm{SiO}_{x}$ layer at the interface between $\mathrm{ZnO}$ and $\mathrm{Si}$ will deteriorate the PCE of the 2-terminal tandem cell.

However, a 4-terminal design has shown a good performance for other junctions and has the advantage of not requiring a current-matching between top and bottom cells. We have shown that InGaN/Si 4-terminal tandem cell can achieve a PCE near to $30 \%$, taking into account a realistic and feasible structural parameters.

This work has been supported by the French National Research Agency (ANR) under the NOVAGAINS contract ANR12-PRGE-0014-01.

\section{References}

1. F. Meillaud, A. Shah, C. Droz, E. Vallat-Sauvain, C. Miazza, Sol. Energy Mater. Sol. Cells 90, 2952 (2006)

2. R. Kapusta, Press release: Alta Devices Achieves $31.6 \%$ Solar Energy Efficiency Record; Changes the Fundamental Economics for Unmanned Aerial Vehicles (2016)

3. J. Bebon, Press release: NREL, CSEM Jointly Set New Efficiency Record with Dual-Junction Solar Cell (2015)
4. I. Vurgaftman, J.R. Meyer, L.R. Ram-Mohan, J. Appl. Phys. 89, 5815 (2001)

5. I. Vurgaftman, J.R. Meyer, J. Appl. Phys. 94, 3675 (2003)

6. J. Wu, W. Walukiewicz, K.M. Yu, J.W. Ager, E.E. Haller, H. Lu, W.J. Schaff, Appl. Phys. Lett. 80, 4741 (2002)

7. J. Wu, W. Walukiewicz, K.M. Yu, W. Shan, J.W. Ager, E.E. Haller, H. Lu, W.J. Schaff, W.K. Metzger, S. Kurtz, J. Appl. Phys. 94, 6477 (2003)

8. B.W. Liou, Thin Solid Films 520, 1 (2011)

9. K. Pantzas, Y. El Gmili, J. Dickerson, S. Gautier, L. Largeau, O. Mauguin, G. Patriarche, S. Suresh, T. Moudakir, C. Bishop, A. Ahaitouf, T. Rivera, C. Tanguy, P. Voss, A. Ougazzaden, J. Cryst. Growth 370, 57 (2013)

10. D. Holec, Y. Zhang, D.V.S. Rao, M.J. Kappers, C. McAleese, C.J. Humphreys, J. Appl. Phys. 104, 12 (2008)

11. D. Holec, P.M.F.J. Costa, M.J. Kappers, C.J. Humphreys, J. Cryst. Growth 303, 314 (2007)

12. S. Srinivasan, L. Geng, R. Liu, F.A. Ponce, Y. Narukawa, S. Tanaka, Appl. Phys. Lett. 83, 5187 (2003)

13. M. Arif, W. Elhuni, J. Streque, S. Sundaram, S. Belahsene, Y. El Gmili, M. Jordan, X. Li, G. Patriarche, A. Slaoui, A. Migan, R. Abderrahim, Z. Djebbour, P. Voss, J. Salvestrini, A. Ougazzaden, Sol. Energy Mater. Sol. Cells 159, 405 (2017)

14. J. Bai, T. Wang, S. Sakai, J. Appl. Phys. 90, 1740 (2001) 
15. N.G. Young, R.M. Farrell, Y.L. Hu, Y. Terao, M. Iza, S. Keller, S.P. DenBaars, S. Nakamura, J.S. Speck, Appl. Phys. Lett. 103, 173903 (2013)

16. P.G. Moses, C.G. Van De Walle, Appl. Phys. Lett. 96, 2 (2010)

17. W. El-Huni, A. Migan, Z. Djebbour, J.-P. Salvestrini, A. Ougazzaden, Prog. Photovolt.: Res. Appl. 24, 11 (2016)

18. J. Zhao, A. Wang, M.A. Green, Prog. Photovolt.: Res. Appl. 7, 471 (1999)

19. J. Zhao, A. Wang, M.A. Green, Solar Energy Mater. Sol. Cells 66, 27 (2001)
20. H. Liu, Z. Ren, Z. Liu, A.G. Aberle, T. Buonassisi, I.M. Peters, Opt. Express 23, A382 (2015)

21. W. Zhao, L. Wang, J. Wang, Z. Hao, Y. Luo, J. Cryst. Growth 327, 202 (2011)

22. N.G. Young, E.E. Perl, R.M. Farrell, M. Iza, S. Keller, J.E. Bowers, S. Nakamura, S.P. DenBaars, J.S. Speck, Appl. Phys. Lett. 104, 163902 (2014)

23. A. Lanterne, J. Le Perchec, S. Gall, M. Coig, A. Tauzin, Y. Veschetti, Energy Procedia 55, 437 (2014)

Cite this article as: Walid El-Huni, Anne Migan, David Alamarguy, Zakaria Djebbour, Modeling of InGaN/Si tandem cells: comparison between 2-contacts/4-contacts, EPJ Photovoltaics 8, 85502 (2017). 